\title{
Peregangan Abdomen Selama Kehamilan Meningkatkan Diastasis Rectus Abdominus
}

\author{
Abdomen Stretching During Pregnancy Increases Rectal Abdominis Diastasis \\ Martini Fairus \\ Prodi Kebidanan Metro, Poltekkes Tanjungkarang, Indonesia \\ Corresponding author: fairus.toha@gmail.com
}

\begin{abstract}
Kata kunci
Diastasis rectus abdominis, Peregangan abdomen;

Kehamilan.

Abstrak

Latar belakang: Peregangan otot perut (diastasis rectus abdominis) selama kehamilan dan setelah melahirkan cukup tinggi. Dampaknya terjadi penurunan dukungan otot untuk kehamilan berikutnya, kesulitan masuknya bagian presentasi janin ke panggul saat persalinan, inkontinensia urine, dan prolaps organ panggul. Tujuan: mengetahui hubungan peregangan abdomen selama kehamilan dengan kejadian diastasis rectus abdominis. Metode: Rancangan penelitian menggunakan studi cross sectional. Populasi ibu bersalin yang datang ke Bidan Praktik wilayah Lampung Timur berjumlah 32 orang. Pengumpulan data variabel dependen (diastasis rectus abdominis) diukur dengan cara pemeriksaan palpasi. Sedangkan, variabel independen (peregangan abdomen) dengan pengukuran lingkar perut menggunakan pita pengukur dalam meter. Data dianalisis menggunakan uji chi square. Hasil: Hasil analisis diperoleh terdapat hubungan peregangan abdomen selama kehamilan dengan diastasis rectus abdominus $(\mathrm{p}=0.016$, $\mathrm{OR}=2,2$; CI 1.325-29.945). Simpulan: Peregangan abdomen meningkatkan risiko 2.2 kali diastasis rectus abdominus pada ibu setelah melahirkan. Ibu pasca persalinan perlu melakukan upaya pencegahan peregangan abdomen berlebihan sesuai saran tenaga kesehatan.
\end{abstract}

Keyword:

Diastasis rectus abdominis, Abdominal stretch;

Pregnancy

\begin{abstract}
s
Background: Stretching of the abdominal muscles (diastasis rectus abdominis) during pregnancy and after delivery is quite high. The impact is a decrease in muscle support for the next pregnancy, difficulty entering the fetal presentation into the pelvis during labor, urinary incontinence, and pelvic organ prolapse. Objective: to determine the relationship of abdominal stretching during pregnancy with the occurrence of diastasis rectus abdominis. Method: The study design used a cross sectional study. The population of maternity women who came to the Midwife Practice in the East Lampung area was 32 people. The collection of dependent variable data (diastasis rectus abdominis) is measured by palpation checking. Meanwhile, the independent variable (abdominal stretch) by measuring the circumference of the abdomen using a tape measure in meters. Data were analyzed using chi square test. Results: The analysis results obtained there is a relationship between abdominal stretching during pregnancy with diastasis rectus abdominus ( $p=0.016$, OR $=2.2 ;$ CI 1.325-29.945). Conclusion: Abdominal stretch increases the risk of 2.2 times abdominal rectus diastasis in the mother after delivery. Postpartum mothers need to make efforts to prevent excessive abdominal stretching according to the advice of health workers.
\end{abstract}

Copyright () 2019 Jurnal Kesehatan Metro Sai Wawai. All rights reserved. 


\section{Pendahuluan}

Perubahan anatomis akibat kehamilan yang dapat dideteksi pada masa nifas adalah perubahan pada sistem muskuloskletal, terutama perubahan pada otot abdomen atau otot perut (Fraser, 2009). Perubahan otot abdomen tersebut berupa pemisahan otot dinding abdomen bagian depan (anterior) yang disebut diastasis rectus abdominis. Berdasarkan hasil penelitian, pada enam bulan postpartum, ditemukan 39\% wanita dengan diastasis rectus abdominis (Mota, Mascoal, Carita, \& Bo, 2014).

Pemisahan otot rektus abdominis dapat menimbulkan dampak berupa terbentuknya ruang antara otot rektus yang akan diisi oleh peritoneum, fasia, dan lemak yang berakibat hilangnya dukungan otot untuk kehamilan berikutnya. Bobak (2005), menjelaskan selama kehamilan otot dinding perut meregang dan akhirnya kehilangan sedikit tonus otot. Kondisi ini berakibat nyeri punggung berat dan kesulitan masuknya bagian presentasi janin ke panggul saat persalinan pada kehamilan berikutnya (Varney, 2008). Dampak lain berupa disfungsi dasar panggul yang berakibat kesulitan menahan buang air kecil (mengompol) atau inkontinensia urine, inkontinensia tinja bahkan prolaps organ panggul (Lee, 2013). Nyeri punggung banyak dirasakan wanita pada 12 minggu pertama setelah melahirkan (Ostgaard \&Andersson, 1992 dalam Lee, 2013). Sebenarnya kejadian DRA dapat dikurangi, berdasarkan hasil penelitian olahraga selama periode antenatal dapat mengurangi DRA sebesar 35\%, namun belum semua ibu hamil rutin melakukan senam hamil (Benjamin, Water, \& Peiris, 2014).

Kejadian mengompol berdasarkan hasil penelitian ditemukan sekitar $45 \%$ wanita akan mengompol pada tujuh tahun postpartum, dan $27 \%$ wanita yang awalnya mengompol pada periode postpartum dini, ternyata $31 \%$ kembali menjadi mengompol pada periode selanjutnya. Kondisi ini dikaitkan dengan kondisi diastasis rectus abdominis (Wilson et al, 2002 dalam Lee, 2013).

Insiden diastasis rectus abdominis cukup tinggi. Diperkirakan $100 \%$ wanita memiliki beberapa tingkat diastasis rectus abdominis pada trimester ketiga (Giliard dan Brown 1996) dan 66\% dari wanita dengan diastasis rectus abdiminis memiliki beberapa tingkat disfungsi dasar panggul (Spitznagle et al, 2007 dalam Powell, 2009). Lokasi diastasis recti abdominis terdapat disepanjang linea alba, $52 \%$ terletak diatas umbilicus dan $11 \%$ terletak di bawah umbilikus (Boissonnault \& Blashchak, 1988).

Di Indonesia belum diperolah angka kejadian diastasis rectus abdominis. Akan tetapi, berdasarkan hasil observasi peneliti terhadap 5 orang ibu nifas yang datang ke bidan praktik diperoleh hasil $100 \%$ memiliki diastasis rekti dengan tingkat yang berbeda-beda yaitu, 2 orang memiliki derajat diastasis rektus abdominis $2 / 2,1$ orang memiliki derajat diastasis rectus abdominis $1 / 2$ dan 2 orang memiliki derajat diastasis rectus abdominus 2/3. Kemudian dari 5 ibu nifas semua sering merasakan nyeri punggung selama kehamilan dan setelah persalinan.

Penelitian ini mengkaji hubungan peregangan abdomen selama kehamilan dengan kejadian diastasis rectus abdominis pada ibu bersalin. Meskipun menurut hasil penelitian tidak ada faktor risiko yang jelas terkait penyebab DRA, dan tidak ada perbedaan dalam laporan nyeri lumbopelvic antara kelompok dengan dan tanpa DRA (Sperstad, Tennfjord, Hilde, Engh, \& Bo, 2016). Namun, faktor-faktor seperti tonus otot, latihan otot perut setelah kehamilan, paritas, jarak kehamilan, dan peregangan abdomen yang berlebihan pada kehamilan misalnya pada kehamilan kembar diduga merupakan faktor risiko terjadinya DRA (Varney, 2008).

Peregangan abdomen yang berlebihan seperti pada kehamilan kembar atau kehamilan dengan polihidramnion mempengaruhi derajat diastasis rectus abdominis. Dijelaskan bahwa diastasis rectus abdominis terjadi akibat tekanan intra abdomen yang terjadi akibat kehamilan. Sementara otot dinding perut tidak dapat dengan mudah menahan tegangan yang diberikan kepadanya. Sehingga, otot perut atau rektus terpisah digaris tengah, dan membentuk diastasis recti dengan lebar bervariasi. Pada kondisi yang parah banyak bagian dari dinding uterus anterior yang hanya tertutup oleh selaput kulit, 


\section{Peregangan Abdomen Selama Kehamilan Meningkatkan Diastasis Rectus Abdominus

fasia yang menipis dan peritoneum (Cunningham, 2005). Besarnya peregangan perut dilakukan dengan pengukuran lingkar perut atau abdomen.

Pengukuran lingkar perut merupakan instrumen penapisan tambahan untuk menentukan setiap penyimpangan dari nilai normal setelah minggu 34 gestasi. Pengukuran lingkar abdomen bermanfaat untuk mengetahui ibu hamil memiliki uterus dengan ukuran yang berlebih seperti pada kehamilan kembar atau polihidramnion (Varney, 2008.). Pengukuran lingkar abdomen dengan mengelilingi tubuh wanita menggunakan meteran setinggi umbilikus. Umumnya ukuran lingkar abdomen yang dianggap normal adalah dua inchi dibawah usia minggu gestasi. Sebagai contoh bahwa ibu hamil dengan usia kehamilan 34 minggu, maka ukuran lingkar abdomen normal adalah 32 inchi $(81 \mathrm{~cm})$. Ibu hamil dengan usia gestasi 40 minggu, maka ukuran lingkar abdomen normal adalah 38 inchi $(96.5 \mathrm{~cm})$. Ukuran lingkar abdomen yang dianggap melebihi normal adalah lebih dari 100 atau 39,5 inchi pada minggu-minggu gestasi akhir. Pengukuran lingkar abdomen mungkin tidak akurat akibat postur tubuh yang berbeda-beda, namun ukuran ini cukup akurat untuk dimanfaatkan sebagai instrumen penapisan secara kasar, khususnya dalam situasi akses instrumen diagnostik modern yang terbatas (Varney, 2008). Artikel ini memberikan informasi hasil penelitian yang bertujuan membuktikan hubungan peregangan abdomen selama kehamilan dengan kejadian diastasis rectus abdominis.

\section{Metode}

Penelitian ini menggunakan rancangan studi cross sectional. Rancangan penelitian untuk membuktikan hubungan peregangan abdomen selama kehamilan dengan kejadian diastasis rectus abdominis. Populasi penelitian seluruh ibu yang melahirkan di Bidan Praktik Mandiri wilayah Lampung Timur. Jumlah sampel minimal dihitung menggunakan uji hipotesis terhadap dua proporsi menurut Lemeshow (2011) diperoleh 32 ibu bersalin. Pengambilan sampel menggunakan cara nonprobability sampling dengan jenis consecutive sampling. Semua subyek yang datang dan memenuhi kriteria pemilihan dimasukkan dalam subyek penelitian sampai jumlah subyek yang diperlukan terpenuhi. Kriteria inklusi pada penelitian meliputi, ibu bersalin dengan usia kehamilan matur $\geq 37$ minggu dan sampai 42 minggu, presentasi kepala, ketuban belum pecah, dan bersedia menjadi subyek penelitian. Kriteria eksklusi meliputi ibu bersalin dengan komplikasi seperti hipertensi, preeklampsia, diabetes, mengalami perdarahan dan atau mengalami trauma persalinan.

Pengumpulan data variabel dependen dilakukan dengan cara observasi hasil palpasi untuk mengetahui derajat diastasis rectus abdominis. Sedangkan variabel independen peregangan abdomen diukur dengan cara pengukuran lingkar perut menggunakan pita pengukur dengan hasil ukur meter. Hasil pengukuran variabel peregangan abdomen dikategorikan peregangan abdomen normal, bila lingkar abdomen 2 inchi lebih rendah dari usia kehamilan, dan peregangan abdomen dianggap berlebih bila lingkar abdomen kurang dari 2 inchi lebih rendah dari usia gestasi, atau sama dengan usia gestasi atau lebih dari usia gestasi. Pengukuran dilakukan dengan observasi . Observasi untuk pengukuran variabel peregangan abdomen yang dilakukan satu kali. Observasi terhadap variabel dependen, yaitu diastasis rectus abdominis dilakukan satu kali dalam 1 minggu pertama pasca salin.

Analisis data menggunakan analisis univariat dan analisis bivariat. Analisis bivariat dilakukan dengan uji chi-square. Inferensi menggunakan nilai $p$ dengan derajat kepercayaan (confiden interval) 95\%, tingkat kesalahan $(\alpha) 5 \%$ dan interpretasi hubungan sebab akibat antara variabel independen dengan dependen, jika PR $=1$ berarti variabel yang diteliti bukan merupakan faktor risiko untuk terjadinya efek, PR > 1 menunjukkan bahwa variabel yang diteliti merupakan faktor risiko untuk terjadinya efek dan PR $<1$ menunjukkan bahwa variabel yang diteliti merupakan faktor protektif untuk terjadinya efek. Pertimbangan etik penelitian dilakukan setelah mendapat izin dari tempat penelitian dan informed consent dari responden. 


\section{Peregangan Abdomen Selama Kehamilan Meningkatkan Diastasis Rectus Abdominus

\section{Hasil}

Hasil penelitian untuk menjawab tujuan penelitian disajikan pada tabel 1 dan tabel 2 menggunakan analisis univariat dan bivariat. Hasil penelitian pada tabel 1 menunjukkan peregangan perut berlebih lebih banyak $(56,2 \%)$ dari pada peregangan abdomen normal $(43.8 \%)$.

Tabel 2 memperlihatkan dari 32 responden yang memiliki peregangan abdomen berlebih diastasis rektus abdominis berjumlah $56.2 \%$ orang dan responden berjumlah 18 orang tersebut yang mengalami diastasis rektus abdominis berjumlah $77.8 \%$ responden. Responden yang mengalami peregangan abdomen selama kehamilan normal atau tidak berisiko diastasis rektus abdominis sebanyak $43.8 \%$ orang dan $35.7 \%$ responden mengalami diastasis rektus abdominis.

Hasil uji statistik pada tabel 2 dapat diketahui peregangan abdomen berhubungan dengan kejadian diastasis rektus abdominis ( $p$ value 0.016). Nilai PR sebesar 2.2, artinya ibu dengan peregangan abdomen berlebihan selama kehamilan berisiko 2.2 kali lebih besar untuk mengalami diastasis rektus abdominis setelah kehamilan (bersalin) dibandingkan ibu dengan peregangan abdomen normal (CI 95\% 1.325 - 29.945).

Tabel 1.

Distribusi responden berdasarkan peregangan perut selama kehamilan

\begin{tabular}{lcc}
\hline Variabel & Jumlah & Persentase \\
\hline Peregangan Perut & 18 & $56.2 \%$ \\
Berlebih (lingkar abdomen $<2$ inchi lebih rendah dari usia hamil) & 14 & $43.8 \%$ \\
Normal (lingkar abdomen 2 inchi lebih rendah dari usia hamil) & 14 \\
\hline
\end{tabular}

Tabel 2.

Hubungan peregangan abdomen dengan kejadian diastasis rectus abdominis

\begin{tabular}{|c|c|c|c|c|c|c|c|c|}
\hline \multirow{3}{*}{ Peregangan Abdomen } & \multicolumn{4}{|c|}{ Diastasis Rectus Abdominalis } & \multirow{2}{*}{\multicolumn{2}{|c|}{ Jumlah }} & \multirow{3}{*}{$\begin{array}{c}\mathbf{P} \\
\text { value }\end{array}$} & \multirow{3}{*}{$\begin{array}{c}\text { PR } \\
\text { CI 95\% }\end{array}$} \\
\hline & \multicolumn{2}{|c|}{ Ya } & \multicolumn{2}{|c|}{ Tidak } & & & & \\
\hline & $\mathbf{n}$ & $\%$ & $\mathbf{n}$ & $\%$ & $\mathbf{n}$ & $\%$ & & \\
\hline $\begin{array}{l}\text { Berlebih (lingkar abdomen }<2 \\
\text { inchi lebih rendah dari usia } \\
\text { hamil) }\end{array}$ & 14 & 77.8 & 4 & 22.2 & 18 & 56.2 & 0.016 & 2.2 \\
\hline $\begin{array}{l}\text { Normal (lingkar abdomen } 2 \\
\text { inchi lebih rendah dari usia } \\
\text { hamil) }\end{array}$ & 5 & 35.7 & 9 & 64.3 & 14 & 43.8 & & $\begin{array}{l}(1.325- \\
29.945)\end{array}$ \\
\hline
\end{tabular}

\section{Pembahasan}

Hasil penelitian menunjukkan peregangan abdomen berhubungan dengan kejadian diastasis rektus abdominis ( $p$ value 0.016). Ibu yang mengalami peregangan abdomen berlebihan selama kehamilan berisiko 2.2 kali lebih besar untuk mengalami diastasis rektus abdominis pasca persalinan dibandingkan ibu dengan peregangan abdomen normal (( $\mathrm{PR}=2.2$; CI 95\% 1.325 - 29.945). Hasil penelitian ini menguatkan konsep bahwa peregangan abdomen yang berlebihan mempengaruhi derajat diastasis rectus abdominis (Varney, 2008).

Secara anatomi otot dinding abdomen anterior terdiri atas empat pasang otot yaitu, rektus abdominis, otot obliqus eksternus, otot obliqus internus dan otot transversus abdominis. Otot rektus Abdominis ini terletak memanjang dari simfisis pubis sampai ke sifisternum. Serat otot mengarah keatas sampai ke prosesus sifoideus dan kartilago kostal iga kelima, keenam dan ketujuh. Otot rektus terdapat pada sisi kiri dan kanan dipisahkan oleh garis yang membentang dari simfisis pubis sampai ke prosesus sifoideus yang disebut linea alba. Letak otot rektus abdominis ini membentang 


\section{Peregangan Abdomen Selama Kehamilan Meningkatkan Diastasis Rectus Abdominus

memanjang pada abdomen bagian depan, memungkinkan otot tersebut mudah terpisah ketika mendapat tekanan intra abdominal yang berlebihan (Fraser \& Cooper, 2009).)

Hasil analisis menunjukkan ibu yang mengalami peregangan abdomen berlebihan selama kehamilan berisiko 2.2 kali lebih besar untuk mengalami diastasis rektus abdominis pasca persalinan dibandingkan ibu dengan peregangan abdomen normal ( $(\mathrm{PR}=2.2$; CI $95 \% 1.325-29.945)$. Terdapat responden yang memiliki peregangan abdomen berlebih diastasis rektus abdominis berjumlah $56.2 \%$ dari 32 responden dan ada 18 responden tersebut yang mengalami diastasis rektus abdominis berjumlah $77.8 \%$ orang. Diastasis Rekti Abdominis merupakan pemisahan otot rectus abdominis lebih dari $2,5 \mathrm{~cm}$ pada tepat setinggi umbilikus yang terjadi karena akibat pengaruh hormon terhadap linea alba serta akibat peregangan mekanis dinding abdomen. Selama kehamilan otot dinding perut meregang dan akhirnya kehilangan sedikit tonus otot. Sedangkan, pada ibu post partum terjadi dinding abdomen mengalami distensi yang berkepanjangan yang disebabkan oleh kehamilan, dinding abdomen masih lunak dan kendur. Kembalinya struktur ini ke keadaan normal memerlukan waktu beberapa minggu, Jika otot-ototnya tetap atonik, dinding abdomen akan tetap kendur. Terdapat pemisahan atau diastasis muskulus rektus yang jelas. Pada keadaan ini, dinding abdomen di sekitar garis tengah hanya dibentuk oleh peritoneum, fasia tipis, lemak subkutan dan kulit (Cuningham, 2005).

Disfungsi diastasis recti abdominis ini merupakan permasalahan ibu setelah melahirkan yang memerlukan tindakan khusus, seperti dengan senam abdominal. Senam abdominal atau senam nifas yang dilakukan segera dapat mengurangi diastasis recti abdominalis atau untuk pengembalian otot seperti semula atau prahamil. Senam abdominal lebih diprioritaskan, jika celah antara rectus lebarnya 3 jari atau lebih (Nurwati, 2014). Jika senam nifas tidak dilakukan, dapat memberi dampak pada kehamilan berikutnya, dan dampak yang umum dirasakan berupa rasa nyeri pada punggung akibat kemampuan fleksi dari tulang belakang yang menurun akibat pemisahan otot rektus abdominis tersebut. Dengan demikian penting untuk melakukan pengukuran lingkar abdomen pada ibu hamil dan pasca persalinan untuk deteksi dini sehingga dapat dilakukan pencegahan seoptimal mungkin (Powell,2009).

\section{Simpulan dan saran}

Simpulan penelitian adalah terdapat hubungan antara peregangan abdomen berlebih selama kehamilan dengan kejadian Diastasis Rectus Abdominis. Peregangan abdomen berlebih selama kehamilan dapat meningkatkan risiko sebesar 2,2 kali untuk terjadinya diastasis rectus abdominis. Perlu diterapkan pengukuran lingkar abdomen dalam pemberian asuhan kebidanan pada ibu hamil agar peregangan lingkar abdomen yang berlebih dapat dideteksi segera, sehingga dapat dilakukan pencegahan peregangan abdomen berlebih.

\section{Referensi}

Benjamin, Water, V. D., \& Peiris. (2014). Effects of exercise on diastatis of the rectus abdominis muscle in the antenatal and postnatal periods a systematic review. Physiotherapy, 1-8.

Bobak, et, all. (2005). Buku Ajar Keperawatan Maternitas. Jakarta: EGC.

Boissonnault, J. S., \& Blashchak, M. J. (1988). Incidence of diastasis recti abdominis during the childbearing year. Physical Therapy, 68(7), 1-5.

Cunningham, F. G. (2005). Obstetri willliam (22 ed.). Jakarta: EGC.

Fraser, D. M., and Cooper, M. A. (2009). Buku ajar bidan myles (14 ed.). Jakarta: EGC.

Lemeshow, S, David W, Hosmer Jr, Janelle Klar, Stephen K, , L. (2011). Sampel size determination in health studies a. practical manual. Geneva: World Health Organization. 
Lee Diane, (2013). Diastatis rectus abdominis dan postpartum health, Associates Physiotherapy

Mota, P., Mascoal, A. G., Carita, A., \& Bo, K. (2014). Prevalence and risk factors of diastasis recti abdominis from late pregnancy to 6 months post partum, and relationship with lumbo-pelvic pain. Norwegian School of Sport Sciences, 1.

Nurmawati, E., dkk. (2014). Manfaat penguatan otot transversus abdominis \& muscle pumping ekstremitas inferior terhadap diastasis rekti abdominis pada ibu nifas. Jurnal Ilmiah Kebidanan. 5(1). Juni 2014

Powell, W. (2009). Diastasis recti test dan exercises, mutu system.com/diastasis recti test.

Sperstad, J. B., Tennfjord, M. K., Hilde, G., Engh, M. E., \& Bo, K. (2016). Diastasis recti abdominis during pregnancy and 12 months after childbirth: prevalence, risk, factors, and report of lumbopelvic pain. Original articel, 1-6.

Varney, H., Kriebs, J. M., and Gegor, C. L.,. (2008). Buku Ajar Asuhan kebidanan (4 ed., Vol. 1). Jakarta: EGC. 